\title{
Kanamycin effects on vestibular, auditory, and renal function in mice
}

\author{
VALERIE P. PERDUE, RICHARD G. BURRIGHT, and PETER J. DONOVICK \\ State University of New York, Binghamton, New York
}

\begin{abstract}
We reported previously that agonistic and discrimination behavior of HET mice could be disrupted by moderate doses of kanamycin. The present data suggest that, to produce vestibular, auditory, and renal effects, more prolonged or higher doses of this aminoglycoside antibiotic are required, suggesting that behavioral changes may be sensitive early indicators of kanamycin's toxic properties.
\end{abstract}

Kanamycin, one of the aminoglycoside antibiotics, has known side effects causing damage to the auditory, vestibular, and renal systems. Recently, we reported that moderate doses of this drug also altered several classes of behavior (Perdue, Eastman, Burright, \& Donovick, in press). In light of findings that at least some aspects of the changes in renal function in heterogenous (HET) stock mice may be reversible (Engellenner, Rozboril, Perdue, Burright, \& Donovick, 1982), we further examined changes in vestibular, auditory, and renal systems in a fashion that allowed comparison with our behavioral data. In light of the lack of effects of kanamycin on vestibular function (Experiment 1 of this study) despite the use of a drug-administration regime previously shown to be effective in behavioral studies (Perdue et al., in press), we extended the administration of kanamycin for Experiments 2 and 3 (auditory and renal functions).

\section{EXPERIMENT 1: VESTIBULAR FUNCTIONING}

\section{Method}

We used 40-50-day-old male HET (Fuller, 1979) mice $(n=46)$ maintained as described previously (Perdue et al., in press) and randomly assigned to receive either $40 \mathrm{mg} / \mathrm{kg}$ of kanamycin $(\mathrm{n}=$ $24)$ or saline $(n=22)$ injections for 21 days. Forty-eight hours after the last injection, we placed approximately half of the animals from each group on top of a horizontal hand-held wiremesh screen and recorded the time required for them to crawl to an edge of the screen. Individual mice were then placed on a vertical hand-held screen and the time required for each to climb to

We thank: Norma Slepecky of the Department of Otorhinolaryngology, SUNY Upstate Medical Center, for performing the necessary histology, Richard Pastore for the use of audiometric equipment, and Steven Bloom for assistance in data collection in Experiment 2; and Carolyn Diehl and Julie Koch for assistance in data collection in Experiments 1 and 3. This research was supported in part by funds from NSF Grant DAR 7911233 and by BRSG Grant S07RR07149-06 awarded by the Biomedical Research Support Grant Program, Division of Research Resources, NIH. V.P.P. is currently at the Department of Psychiatry, SUNY Upstate Medical Center, Syracuse, NY 13210. Reprint requests should be sent to Peter J. Donovick, Department of Psychology, SUNY, Binghamton, NY 13901. the top edge was recorded. Both measures were terminated after $90 \mathrm{sec}$. The remaining half of the animals from each group were placed on a smooth 2.5 -cm-diam cylinder (a rotorod) that rotated at $10 \mathrm{rpm}$ (Fuller \& Herman, 1974). Time on the rotorod was measured, up to a maximum of $60 \mathrm{sec}$, and mode of departure from the rod was judged as either a fall or a jump for each mouse.

\section{Results}

Neither the screen nor the rotorod measurements suggested that administration of kanamycin for 21 days, stopped $48 \mathrm{~h}$ prior to testing, resulted in behaviorally assessable vestibular ototoxicity. On the average, regardless of group, all animals reached the edge of the screen in $13 \mathrm{sec}$ (horizontal and vertical) and maintained their balance on the rotorod for $7 \mathrm{sec}$ before jumping off.

\section{EXPERIMENT 2: AUDITORY PROCESSING}

\section{Method}

We examined the performance of HET mice in an auditorycued active avoidance paradigm and the subsequent cochlear hair loss following administration of kanamycin. Since not all HET mice acquire stable active avoidance performance (McDaniel, Donovick, Burright, \& Fanelli, 1980), we pretrained a group of mice in individual shuttle boxes enclosed in separate, soundattenuating chambers. All testing was conducted in the presence of continuous low-frequency white noise $(66-68 \mathrm{~dB}, \mathrm{C}$ scale) generated by ventilation fans and of a red $25-\mathrm{W}$ overhead light. A high-frequency piezoelectric tweeter was mounted directly above each chamber. Pure sine waves produced by a Wavetec generator and delivered through the tweeter served as the conditioned stimulus (CS) for this shock-motivated active avoidance task. The unconditioned stimulus (UCS), scrambled shock to the floor grids, was provided by a constant-current shocker.

Procedure. Each mouse received 50 avoidance trials per day with the onset of a $15-\mathrm{kHz}$ tone as the CS. A variable intertrialinterval (ITI) schedule (ITI $=25-65 \mathrm{sec}$; mean $=45 \mathrm{sec}$ ) was employed; ITI shuttling was punished with a $1.5-\mathrm{mA}$ footshock. During the trial, if a shuttle response did not occur within the first $10 \mathrm{sec}$ of the tone, a $1.5-\mathrm{mA}$ shock was delivered to the grid floor. Shock and tone remained on until the subject had crossed to the opposite side of the chamber. A shuttle response during either the CS (avoidance) or the CS+UCS (escape) periods terminated the trial.

Eight weeks of $400-\mathrm{mg} / \mathrm{kg}$ subcutaneous injections of kanamycin $(n=2)$ or saline $(n=2)$ began after each mouse had 
reached a stability criterion of 30 or more successful avoidance responses with a ratio of punished ITI crossings to avoidances of less than 0.6. Injections occurred immediately before each behavioral testing session. Testing continued for 3 weeks after termination of injections, as a means of monitoring the consequences of prolonged exposure to kanamycin and any subsequent reversibility of such changes after cessation of injections.

Histology. The mice were killed with Nembutal; the bullas were removed, and the cochleas were fixed in $2 \%$ glutaraldehyde in $0.1 \mathrm{M}$ phosphate buffer $(\mathrm{pH}=7.0)$, washed in $0.1 \mathrm{M}$ phosphate buffer, and dehydrated in $70 \%$ ethanol. The cochleas were dissected in $70 \%$ ethanol, and pieces of the organ of Corti were mounted in glycerin on glass slides.

These surface preparations were examined with a light microscope (Zeiss Nomarski differential interface contrast). A hair cell was counted as missing if there was a scar formed at the level of the reticular lamina. The number of hair cells was determined for each microscope field $(0.5 \mathrm{~mm}$ of the cochlea was observed with a $40 \mathrm{x}$ objective), and the percentage of missing hair cells was calculated (Hawkins, Johnssond, \& Aran, 1969).

\section{Results}

Once established prior to injections, auditory-cued avoidance behavior of control and drug-treated mice was stable for 2.5 months of 50-trials/day testing. That is, both sets of mice consistently met the performance criterion described above throughout the 8-week injection period. The animals generally avoided the shock on at least $80 \%$ of the trials and received fewer than 20 shocks between trials. There was a precipitous change in the discrimination behavior of both drug-treated mice approximately 2 weeks after the cessation of the 8 weeks of injections (Figure 1). This change is expressed by the dramatic increase in punished ITI activity. In contrast, the discrimination behavior of control mice did not change over this period of time. Although we have not addressed the question of when hearing first decays, these data demonstrate that prolonged administration of kanamycin was necessary to disrupt behavior in this auditory-discrimination task using a midrange tone $(15 \mathrm{kHz})$.

Subsequently, cochleograms revealed that both mice that received kanamycin injections had almost complete loss of outer hair cells and also suffered greater than $40 \%$ destruction of inner hair cells.

\section{EXPERIMENT 3: URINE PRODUCTION}

\section{Method}

As a measure of fluid metabolism, and thus of kidney function, we examined the fluid intake and urine metabolism in metabolic cages of 20 male HET mice, which were 60-70 days of age at the beginning of the experiment and were assigned randomly to four equal-sized groups. They received subcutaneous injections of 400,600 , or $800 \mathrm{mg} / \mathrm{kg}$ of kanamycin, or of an equal volume of saline, 6 days/week for 8 weeks. Each week, the mice were placed in metabolic cages (Engellenner et al., 1982) for $48 \mathrm{~h}$. The animals were injected immediately prior to being placed in and immediately following removal from metabolic cages. Injections were not given while the mice were in the metabolic cages. Note that the cumulative dose, rather than the daily dose, is reported to be the critical variable in determining the toxic properties of the aminoglycoside antibiotics (Kreis, 1966). Changes in body weight, fluid consumption, and urine production were measured for the $48-h$ observation period.

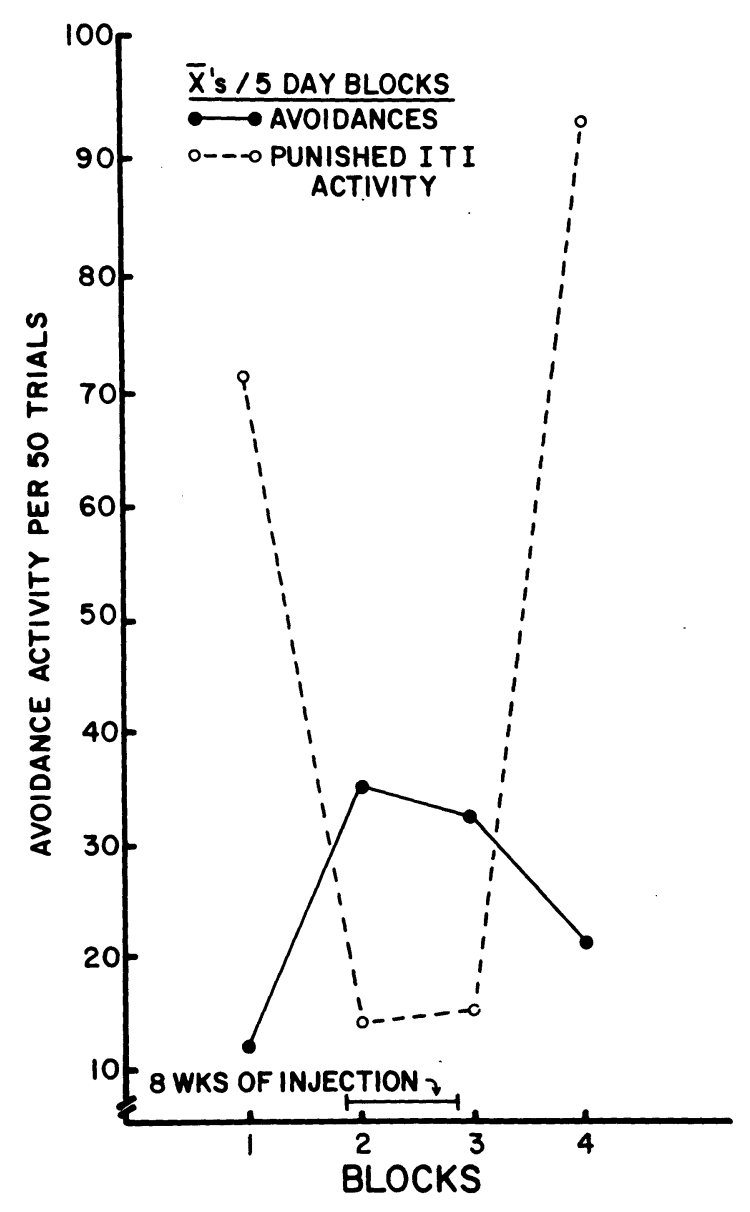

Figure 1. Auditory-cued avoidance performance, prior to, during, and following 8 weeks of kanamycin injections.

These measures were continued for the 8 weeks of drug treatment and for 4 weeks after termination of all injections.

\section{Results}

During the period of injection, there was some suggestion of elevation in urine production in the $800-\mathrm{mg} / \mathrm{kg}$ kanamycin group. However, following termination of injections, any hints of group differences disappeared. There were no indications of group differences in fluid consumption. Thus, even when administered high doses of kanamycin for a prolonged period, HET mice failed to show persistent changes in fluid regulatory capacity (see also Engellenner et al., 1982).

\section{DISCUSSION}

These data suggest that HET mice are relatively resistant to the oto- and nephrotoxic properties of kanamycin, compared with other species (e.g., Harpur \& D'Arcy, 1975; Hawkins, 1973; Prosen, Petersen, Moody, \& Stebins, 1978). We reported previously (Perdue et al., in press) that agonistic behavior and maze performance were disrupted by only 3 weeks of kanamycin administration. The present findings, however, suggest that, in HET mice, prolonged and high doses are necessary to induce the more commonly recognized side effects of these drugs. Although not all behaviors that we examined were affected, the finding that 
some aspects of social behavior and performance of learned tasks were altered by relatively low doses of kanamycin points to the need for further investigation of potential behavioral sequelae of aminoglycoside antibiotics, as well as other commonly prescribed drugs.

\section{REFERENCES}

Engellenner, W. J., Rozboril, L., Perdue, V. P., Burright, R. G., \& Donovick, P. J. (1982). A simple inexpensive metabolic cage for mice. Physiology \& Behavior, 28, 177-179.

Fuller, J. L. (1979). Fuller BWS lines: History and results. In M. E. Hahn, C. Jensen, \& B. C. Dudek (Eds.), Development and evolution of brain size: Behavioral implications. New York: Academic Press.

Fuller, J. L., \& Herman, B. H. (1974). Effect of genotype and practice upon behavioral development in mice. Developmental Psychobiology, 7, 21-30.

Harpur, E. S., \& D'Arcy, P. F. (1975). The quantification of kanamycin ototoxicity in the rat using conditioned tone discrimination. Journal of Pharmacy and Pharmacology, 27, 907-913.
Hawkins, J. E., Jr. (1973). Comparative otopathology: Aging, noise and ototoxic drugs. Advances in Oto-Rhino-Laryngology, 20, 125-141.

Hawkins, J. E., Jr., Johnsson, L., \& Aran, J. (1969). Comparative tests of gentamicin ototoxicity. Journal of Infectious diseases, 119, 417-425.

KREIS, B. (1966). Kanamycin ototoxicity in adults. Annals of the New York Academy of Sciences, 132, 957-983.

McDaniel, J. R., Donovick, P. J., Burright, R. G., \& FANELli, R. J. (1980). Genetics, septal lesions and avoidance behavior in mice. Behavioral and Neural Biology, 28, 285-299.

Perdue, V. P., Eastman, W. W., Burright, R. G., \& Donovick, P. J. (in press). Behavioral analysis of kanamycin administration to mice. Neurotoxicology.

Prosen, C. A., Petersen, M. R., Moody, D. B., \& Stebins, W. C. (1978). Auditory thresholds and kanamycin-induced hearing loss in the guinea pig assessed by a positive reinforcement procedure. Journal of the Acoustical Society of America, 63, 559-566.

(Manuscript received for publication January 9, 1984.)

\title{
ANNOUNCEMENTS

\author{
Call for Papers \\ Society for Computers in Psychology
}

The 14th annual meeting of the Society for Computers in Psychology will be held on November 7, 1984 (the day before the Psychonomic Society meeting), in San Antonio, Texas. The deadline for submission of papers, symposia, and posters is July 1,1984 . Further information may be obtained from and submissions sent to:

\author{
Walter Schneider \\ Department of Psychology \\ University of Illinois \\ 603 E. Daniel Street \\ Champaign, IL 61820
}

(217)333-6819

\section{Computer Conference Student Paper Competition}

The Society for Computers in Psychology will continue to sponsor an award for the outstanding student paper submitted for presentation at the annual meeting. Although the primary emphasis of the conference is the use of computers in on-line experimental applications, student papers in any area of application of computers to psychology are welcome. Papers may be theoretical, experimental, or applied in approach. Eligibility is open to students currently enrolled in undergraduate or graduate courses, or students who graduated in 1984 and have done the work as part of a course, thesis, or other student research project. All papers submitted for the conference (including those multiply authored) in which the major contribution has been made by a student are eligible for consideration and will be considered for presentation at the conference and subsequent publication. The outstanding student paper will be presented at the 1984 conference and published in the Computer Conference Proceedings. Also, the author will receive a complimentary 1-year membership in the Society for Computers in Psychology, a complimentary 1-year subscription to Behavior Research Methods, Instruments, \& Computers, and a \$50 cash prize. The deadline for papers is July 1, 1984. Eligible papers should be submitted in quadruplicate. A cover sheet should include the author's name, mailing address, telephone number, and academic affiliation, a 50word abstract, and a note stating that the paper is to be considered for the student award. These materials should be sent to Walter Schneider at the above address. 